\title{
The potential and scope of the microwave tool; A case study on the synthesis of phosphinates
}

\author{
György Keglevich* and Nóra Zsuzsa Kiss \\ Department of Organic Chemistry and Technology, Budapest University of Technology and Economics, \\ 1521 Budapest, Hungary; gkeglevich@mail.bme.hu; zsnkiss@mail.bme.hu \\ * Correspondence: gkeglevich@mail.bme.hu; Tel.: +36-1-463-1111/5883 \\ Academic Editor: name \\ Received: date; Accepted: date; Published: date
}

\begin{abstract}
Microwave (MW) irradiation has had a positive impact also on organophosphorus chemistry. This is demonstrated via the synthesis of phosphinates from phosphinic acids. The scope and limitations of the use of the MW technique, along with the modeling of the distribution of the beneficial effect of the local overheatings and the prediction of the acceleration is discussed. All these are possible on the basis of the energetics calculated for a selected esterification by quantum chemical methods.
\end{abstract}

Keywords: phosphinic acid; phosphinate; microwave; ionic liquid; green chemistry; scope and limitation of the use of MW; modeling the effect of MW; conformation

\section{Introduction}

The use of microwave (MW) reactors spread fast in synthetic organic chemistry, and for today, it knocks at the door of industry [1,2]. Organophosphorus chemistry also profited much from this "green" tool allowing more efficient reactions, new transformations, or simplification of catalysts or catalyst systems [3-6]. The new synthetic protocols including refunctionalizations afforded phosphonic-, phosphinic- and phosphine oxide derivatives comprising P-heterocyclies [7].

The role of MWs in organic syntheses induced disputes, however, these days nonthermal theories are generally rejected $[8,9]$. Considering thermal effects, local overheatings occurring statistically in the bulk of the mixture may be responsible for the beneficial effect of MWs [10].

In this paper, we summarize the possible methods for the synthesis of phosphinates showing the advantages of the MW-assisted direct esterifications. Then, the theoretical aspects of a few related model reactions are explored to demonstrate the scope of the application of the MW tool. Finally, our results on the modeling of the distribution of the local overheatings, and the prediction of their effect on an esterification selected are summarized.

\section{Results and Discussion}

\subsection{Possible syntheses of phosphinates with stress on the MW-assisted methods}

The phosphinates, useful intermediates in synthetic organic chemistry [11,12] are, in most cases, synthesized by the reaction of phosphinic chlorides with alcohols in the presence of a base in an apolar solvent [12]. This classical protocol is exemplified by the esterification of 1-chloro-3-phospholene 1-oxides (Scheme 1/A) [13,14]. The use of phosphinic chlorides means cost, and causes environmental burden due to the $\mathrm{HCl}$ formed. Moreover, the method under discussion is not atom efficient. Another possibility is the reaction of phosphinic acids with alcohols in the presence of the cyclic propylphosphonic anhydride, called the $\mathrm{T} 3 \mathrm{P}^{\circledR}$ reagent [15]. Remaining with the heterocyclic models using 1.1 equivalents of the $\mathrm{T} 3 \mathrm{P}^{\circledR}$ reagent at $25^{\circ} \mathrm{C}$, the 1-hydroxy-3-phospholene 1-oxides could be converted in yields of $76-95 \%$ to the corresponding phosphinates (Scheme 1/B) [16]. The ${ }^{\mathrm{T}} 3 \mathrm{P}^{\oplus}$-promoted esterification was then extended to the reaction of the saturated 
1-hydroxyphospholane oxides [17], and the mechanism of the esterification was evaluated by theoretical calculations [18]. This is an elegant method, however, the $\mathrm{T}^{\mathrm{P}}{ }^{\circledR}$ reagent is expensive, and the conversion is not atom-efficient due to the waste of $\operatorname{PrP}(\mathrm{O}) \mathrm{OH}-\mathrm{O}-\operatorname{Pr} \mathrm{P}(\mathrm{O})-\mathrm{O}-\mathrm{PrP}(\mathrm{O}) \mathrm{OH}$. The next option is the alkylating esterification of the cyclic phosphinic acids. This procedure involves the MW-assisted solvent-free reaction of 1-hydroxy-3-phospholene oxides (Scheme 1/C) or 1-hydroxyphospholane oxides, or even a 1-hydroxy-1,2,3,4,5,6-hexahydrophosphinine oxide with alkyl halides in the presence of $\mathrm{K}_{2} \mathrm{CO}_{3}$ as the base under S-L phase transfer (PT) catalytic conditions. The cyclic phosphinates were obtained in yields of 73-95\% [19-21]. It was found that in case of using alkyl halides with normal reactivity (e.g. EtI), the combined use of MW and PT catalysis is advantageous due to synergism. In case of alkyl halides with increased reactivity (e.g. $\mathrm{BnBr}) \mathrm{MW}$ irradiation was enough, and there was no need for a PT catalyst. Although this route is attractive, the use of alkyl halides means cost and generates HX waste decreasing the atom efficiency. The last possibility studied by us, the direct esterification of phosphinic acids by alcohols that normally does not take place. However, on MW irradiation 1-hydroxy-3-phospholene oxides underwent esterification with a series of alcohols used in a 15-fold quantity. The reactions required an irradiation at $220-235{ }^{\circ} \mathrm{C}$ for $2-4 \mathrm{~h}$ to afford the 1-alkoxy-3-phospholene oxides in yields of $57-95 \%$ (Scheme 1/D). Moreover, the MW-assisted direct esterifications could be extended to hydroxyphospholane and hydroxy-hexahydrophosphinine oxides [20,22-24]. Although this new protocol of ours requires the simplest reagents and is atom-efficient, the reaction temperature of $\geq 220^{\circ} \mathrm{C}$ is a drawback.

Xiang at al. also elaborated efficient esterifications of phosphinic acids with alcohols. They applied copper catalyst or activating agents [25-27].

In summary, always the particular situation suggests, which approach is to be used for the preparation of phosphinates [28,29].

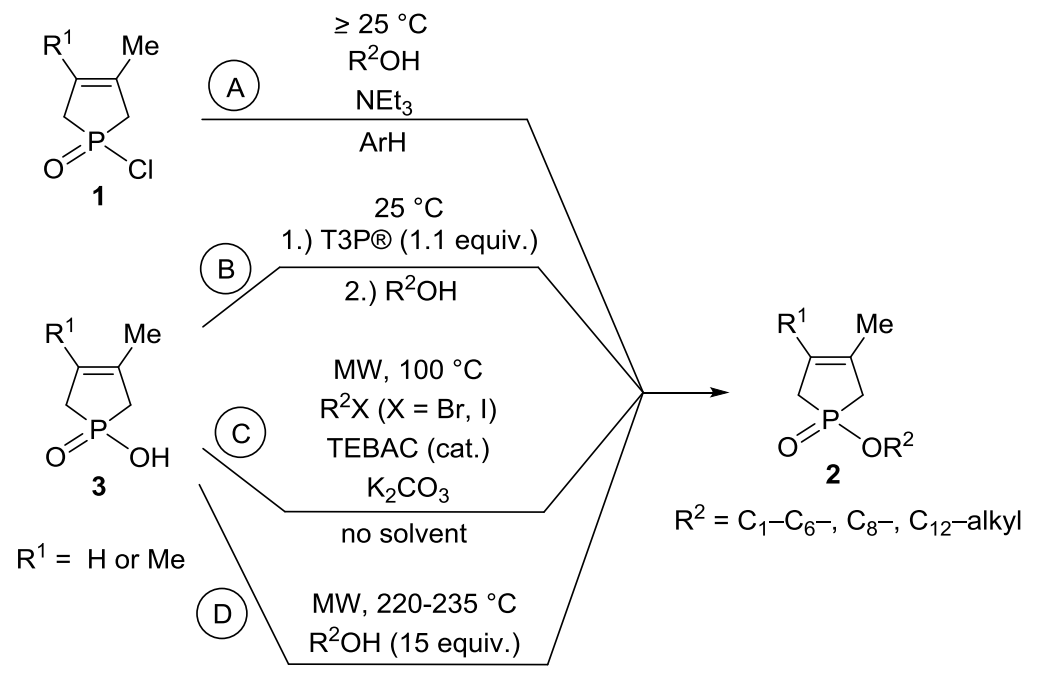

Scheme 1. Possible routes for the conversion of 5-ring phosphinic acids to the corresponding phosphinates.

Other phosphinates that were prepared are shown in Figure 1.
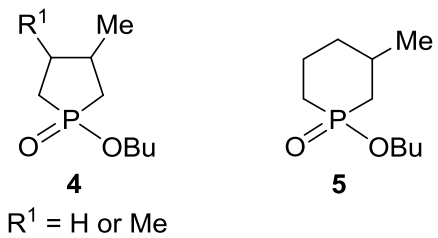

Figure 1. The saturated cyclic phosphinates prepared. 
We were not satisfied with the average yield of $65 \%$ for the phosphinates. According to a new trend, ionic liquids are used in a catalytic quantity, to enhance a wide range of organic reactions [30-32]. Carrying out the direct esterification of 1-hydroxy-3-phospholene oxide and the saturated ring phosphinic acids in the presence of $10 \%$ of $[\mathrm{bmim}]\left[\mathrm{PF}_{6}\right]$ as an additive, the reactions became more efficient: the conversions were, in most cases, quantitative and the yields ca. $23 \%$ higher already at a lower temperature and in a shorter reaction time [33]. It is noteworthy that although the 1-hydroxy-3-phospholene oxide did not undergo esterification with substituted phenols, not even under vigorous $\mathrm{MW}$ conditions, in the presence of $10 \%$ of $[\mathrm{bmim}]\left[\mathrm{PF}_{6}\right]$, the reaction did take place in acceptable (52-64\%) yields [34]. Reasonable results were obtained in the MW-assisted direct esterification of phenylphosphonic acid-monoesters [35]. The efficiency of this protocol is to be further improved.

\subsection{Theoretical aspects: mechanism, energetics, scope and limitation of the application of MWs}

The classical acid-catalyzed mechanism for the direct esterification of phosphinic acids is shown in Scheme 2/Route A. B3LYP/6-31++G(d,p) calculations suggested an alternative pathway involving a four-centered transition state (Scheme 2/Route B) [23].

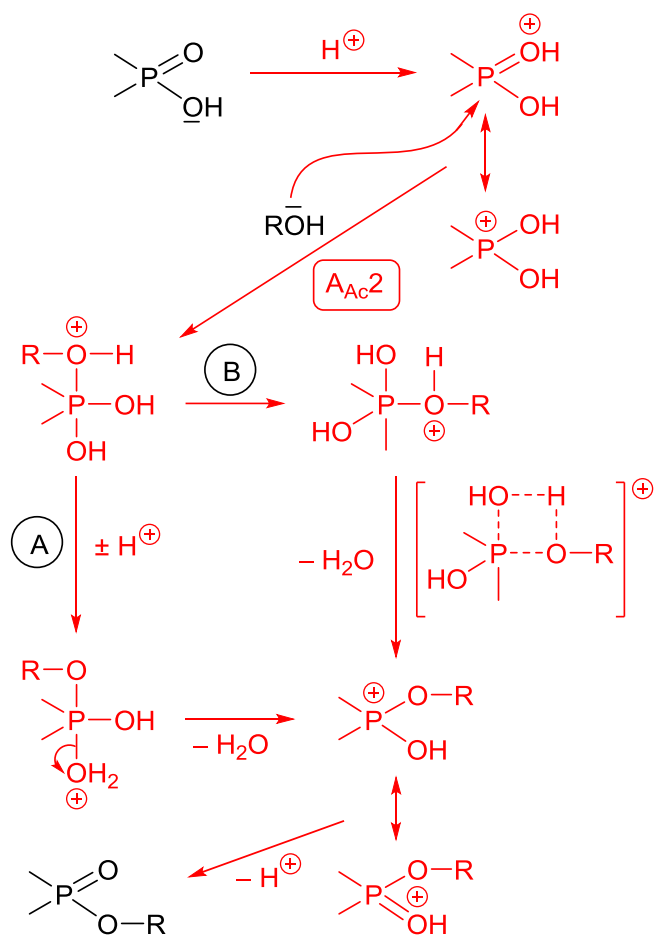

\section{Scheme 2 .}

Then, the energetics were calculated for selected model reactions. The results are summarized in Table 1.

Considering the esterification of 1-hydroxy-3-phospholene oxide with butanol (1) and, as a comparison, that of acetic acid with methanol (2), the B3LYP/6-31++G(d,p) calculations suggested that both reactions are almost thermoneutral. At the same time, the phosphinylation with the 1-hydroxy-3-phospholene oxide has a significantly higher enthalpy of activation $\left(\Delta H^{\sharp}=\right.$ $\left.101.7 \mathrm{~kJ} \mathrm{~mol}^{-1}\right)$ than the acylation with methanol $\left(75.0 \mathrm{~kJ} \mathrm{~mol}^{-1}\right)$ [23]. The former barrier was found even higher $\left(135.0 \mathrm{~kJ} \mathrm{~mol}^{-1}\right)$ by more accurate calculations applying the explicit-implicit solvent model [36]. Obviously, the latter value may be closer to reality. The next model was the esterification of the cyclic phosphinic acid with thiobutanol (3). This reaction remained incomplete $(33 \%$ conversion) on $\mathrm{MW}$ irradiation at $200{ }^{\circ} \mathrm{C}$. Calculations referred to a high $\Delta H^{\sharp}$ of $145.4 \mathrm{~kJ} \mathrm{~mol}^{-1}$, and to a significant extent of endothermicity $\left(\Delta H^{0}=48.5 \mathrm{~kJ} \mathrm{~mol}^{-1}\right)$ [37]. Finally, let us regard the amidation 
of the phosphinic acid with hexylamine. Similarly to the previous model, the amidation also stopped at a low conversion of $30 \%$. Although this transformation was also endothermic $\left(\Delta H^{0}=\right.$ $\left.32.6 \mathrm{~kJ} \mathrm{~mol}^{-1}\right)$, the $\Delta \mathrm{H}^{\sharp}$ was rather low $\left(79.4 \mathrm{~kJ} \mathrm{~mol}^{-1}\right)[38]$.

Table 1. The energetics calculated for esterifications, a thioesterification and an amidation

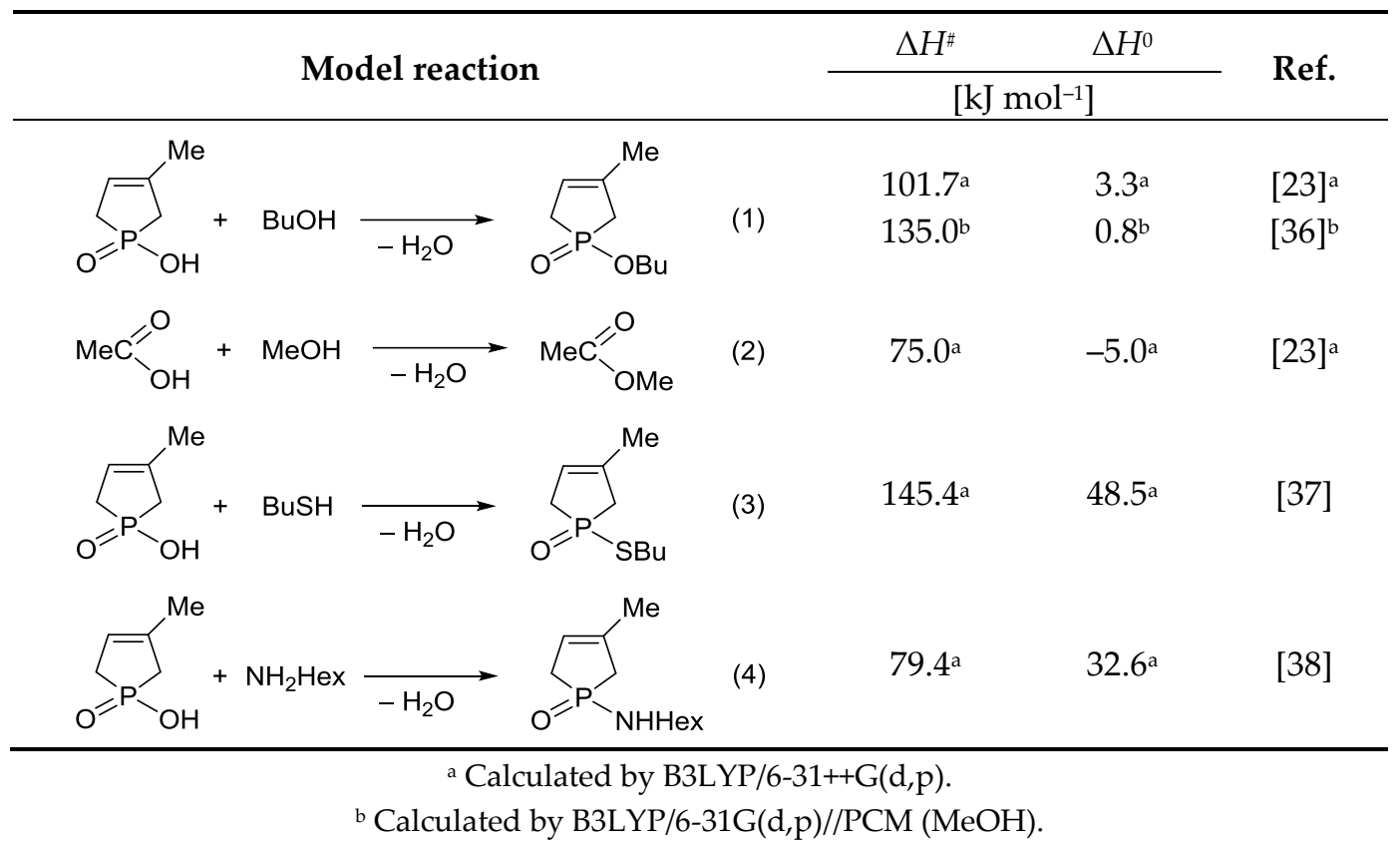

The role of MWs is to enhance reactions with higher $\left(>130 \mathrm{~kJ} \mathrm{~mol}^{-1}\right)$ enthalpy of activation. The MW assistance is optimal for thermoneutral reactions. Endothermicity works against the beneficial effect of MWs [6,39]. This may be possible due to the statistically occurring local overheating effect (that may be in the range of $1-60^{\circ} \mathrm{C}$ ) in the bulk of the reaction mixture. Assuming an overheated segment up to $30 \%$, the effect is significant.

\subsection{Modeling and calculating the effect of local overheatings}

One key to model the thermal effect of the local overheatings is the Arrhenius equation that makes possible to calculate the individual rate constants in the bulk, and also in the overheated segments. The overall rate constant is the weighted sum of kbulk and the individual $\mathrm{k}^{\mathrm{i}}$ values (where $\mathrm{k}$ is the rate constant). The other key is to model the distribution of the local overheatings. An exponentially decreasing relationship was assumed between the overheatings (selected as 5, 10, 20, $30,40,50$ and $60{ }^{\circ} \mathrm{C}$ ) and the proportion of this segment that was selected as 5, 10, 20, 30, 40 and 50\% [40-42]. Regarding the MW-assisted reaction of 1-hydroxy-3-methyl-3-phospholene oxide with butanol (exhibiting a $\Delta H^{*}$ of $135.0 \mathrm{~kJ} \mathrm{~mol}^{-1}$ ), and comparing the accelerations calculated for different proportion sets with that established experimentally [41], the obtained value of 3.1 matched the calculation assuming an overheated segment of $40 \%$.

\section{Conclusion}

The usefulness of the MW tool was demonstrated via the direct esterification of phosphinic acids. This reaction is reluctant on conventional heating. Our experiences supported by theoretical calculations suggest that MW irradiation may be useful for thermoneutral reactions with high enthalpy of activation. Finally, the distribution of the beneficial local overheatings was modeled, and the extent of the rate enhancement was predicted for the esterification of 1-hydroxy-3-methyl-3-phospholene oxide with butanol.

Acknowledgments: This project was supported by the National Research, Development and Innovation Fund (K119202). 


\section{References}

1. Microwaves in Organic Synthesis, $3^{\text {rd }}$ ed.; de la Hoz, A.; Loupy, A., Eds.; Wiley-VCH: Weinheim, 2012, ISBN: 9783527331161.

2. Milestones in Microwave Chemistry - SpringerBriefs in Molecular Science; Keglevich, G., Ed.; Springer: Switzerland, 2016, ISBN: 978-3-319-30630-8.

3. Guenin, E.; Meziane, D. Microwave assisted phosphorus organic chemistry: A review. Curr. Org. Chem. 2011, 15, 3465-3485, DOI: 10.2174/138527211797374724.

4. Keglevich, G.; Grün, A.; Bálint, E.; Kiss, N.Z.; Jablonkai, E. Microwave-assisted organophosphorus synthesis. Curr. Org. Chem. 2013, 17, 545-554, DOI: 10.2174/1385272811317050009.

5. Keglevich, G. Application of microwave irradiation in the synthesis of P-heterocycles. In Green Synthetic Approaches for Biologically Relevant Heterocycles, Brahmachari, G., Ed.; Elsevier: Amsterdam, 2015; Ch. 20, pp. 559-570, ISBN: 9780128000700.

6. Keglevich, G.; Kiss, N.Z.; Grün, A.; Bálint, E.; Kovács, T. Advantages of the microwave tool in organophosphorus syntheses. Synthesis 2017, 49, 3069-3083, DOI: 10.1055/s-0036-1589031.

7. Kiss, N.Z.; Bálint, E.; Keglevich, G. Microwave-assisted syntheses in organic chemistry. In Milestones in Microwave Chemistry - SpringerBriefs in Molecular Science; Keglevich, G., Ed.; Springer: Switzerland, 2016; Ch. 2, pp. 11-46, ISBN: 978-3-319-30630-8.

8. Yadav, G.D.; Bisht P.M. Fundamental analysis of microwave irradiated liquid-liquid phase transfer catalysis (MILL-PTC): Simultaneous measurement of rate and exchange equilibrium constants in selective O-alkylation of p-text-butylphenol with benzyl chloride. J. Mol. Catal. A: Chem. 2005, 236, 54-64, DOI: 10.1016/j.molcata.2005.04.003.

9. Kappe. C.O.; Pieber, B.; Dallinger, D. Microwave effects in organic synthesis: myth or reality? Angew. Chem. Int. Ed. 2013, 52, 1088-1094, DOI: 10.1002/anie.201204103.

10. Kranjc, K.; Kočevar, M. Microwave-assisted organic synthesis: General considerations and transformations of heterocyclic compounds. Curr. Org. Chem. 2010, 14, 1050-1074, DOI: $10.2174 / 138527210791130488$.

11. Quin, L.D. A Guide to Organophosphorus Chemistry; Wiley \& Sons: New York, 2000, ISBN: 978-0-471-31824-8.

12. Kiss, N.Z.; Keglevich, An overview of the synthesis of phosphinates and phosphinic amides. G. Curr. Org. Chem. 2014, 18, 2673-2690, DOI: 18:2673-2690. doi:10.2174/1385272819666140829011741.

13. Moedritzer, K.; Miller, R.E. 1-Phenoxyphospholene 1-oxides. Phosphorus, Sulfur. 1981, 9, 293-297, DOI: 10.1080/03086648108078253.

14. Keglevich, G.; Petneházy, I.; Miklós, P.; Almásy, A.; Tóth, G.; Tőke, L.; Quin, L.D. Ring expansion in the addition of dichlorocarbene to 2,5-dihydro-1H-phosphole 1-oxides. J. Org. Chem. 1987, 52, 3983-3986, DOI: 10.1021/jo00227a008.

15. Basavaprabhu; Vishwanatha, T.M.; Panguluri, N.R.; Sureshbabu, V.V. Propanephosphonic acid anhydride $\left(\mathrm{T} 3 \mathrm{P}^{\circledR}\right)$ - A Benign reagent for diverse applications inclusive of large-scale synthesis. Synthesis, 2013, 45, 1569-1601, DOI: 10.1055/s-0033-1338989.

16. Jablonkai, E.; Milen, M.; Drahos, L.; Keglevich, G. Esterification of five-membered cyclic phosphinic acids under mild conditions using propylphosphonic anhydride $\left(\mathrm{T}^{\circledR} \mathrm{P}^{\circledR}\right)$. Tetrahedron Lett. 2013, 54, 5873-5875, DOI: 10.1016/j.tetlet.2013.08.082.

17. Jablonkai, E.; Henyecz, R.; Milen, M.; Kóti, J.; Drahos, L.; Keglevich, G. T3P ${ }^{\circledR}$-assisted esterification and amidation of phosphinic acids. Tetrahedron 2014, 70, 8280-8285, DOI: 10.1016/j.tet.2014.09.021.

18. Ábrányi-Balogh, P.; Jablonkai, E.; Henyecz, R.; Milen, M.; Keglevich, G. Theoretical calculations on the mechanism of the $\mathrm{T}^{\circledR} \mathrm{P}^{\circledR}$-promoted esterification and amidation of phosphinic acids. Curr. Org. Chem. 2016, 20, 1135-1142, DOI: 10.2174/1385272820666151218204848.

19. Bálint, E.; Jablonkai, E.; Bálint, M.; Keglevich, G. Alkylating esterification of 1-hydroxy-3-phospholene oxides under solventless MW conditions. Heteroatom Chem. 2010, 21, 211-214, DOI: 10.1002/hc.20596.

20. Keglevich, G.; Bálint, E.; Kiss, N.Z.; Jablonkai, E.; Hegedűs, L.; Grün, A.; Greiner, I. Microwave-assisted esterification of phosphinic acids. Curr. Org. Chem. 2011, 15, 1802-1810, DOI: 10.2174/138527211795656570.

21. Keglevich, G.; Grün, A.; Bálint, E. Microwave irradiation and phase transfer catalysis in C-, O- and N-alkylation reactions. Curr. Org. Synth. 2013, 10, 751-763, DOI: 10.2174/1570179411310050006.

22. Kiss, N.Z.; Ludányi, K.; Drahos, L.; Keglevich, G. Novel synthesis of phosphinates by the microwave-assisted esterification of phosphinic acids. Synthetic Commun. 2009, 39, 2392-2404, DOI: 10.1080/00397910802654880. 
23. Keglevich, G.; Kiss, N.Z.; Mucsi, Z.; Körtvélyesi, T. Insights into a surprising reaction: The microwave-assisted direct esterification of phosphinic acids. Org. Biomol. Chem. 2012, 10, 2011-2018, DOI: 10.1039/C2OB06972E.

24. Kiss, N.Z.; Böttger, É.; Drahos, L.; Keglevich, G. Microwave-assisted direct esterification of cyclic phosphinic acids. Heteroatom Chem. 2013, 24, 283-288, DOI: 10.1002/hc.21092.

25. Xiong, B.; Zeng, K.; Zhang, S.; Zhou, Y.; Au, C.-T.; Yin, S.-F. Copper-catalyzed direct esterification of $\mathrm{P}(\mathrm{O})-\mathrm{OH}$ compounds with phenols. Tetrahedron, 2015, 71, 9293-9298, DOI: 10.1016/j.tet.2015.10.028.

26. Xiong, B.; Hu, C.; Li, H.; Zhou, C.; Zhang, P.; Liu Y.; Tang, K. CDI-promoted direct esterification of $\mathrm{P}(\mathrm{O})-\mathrm{OH}$ compounds with phenols. Tetrahedron Lett, 2017, 58, 2482-2486, DOI: 10.1016/j.tetlet.2017.05.036.

27. Xiong, B.; Cheng, Q.; Hu, C.; Zhang, P.; Liu, Y.; Tang, K. Copper-catalyzed oxidative cross-coupling of $\mathrm{P}(\mathrm{O})-\mathrm{OH}$ compounds with aryl boronic acids. Chem. Select, 2017, 2, 6891-6894, DOI: 10.1002/slct.201700716.

28. Keglevich, G.; Kiss, N.Z.; Mucsi, Z.; Jablonkai, E.; Bálint, E. The synthesis of phosphinates: traditional versus green chemical approaches. Green Process. Synth. 2014, 3, 103-110, DOI: 10.1515/gps-2013-0106.

29. Kiss, N.Z.; Henyecz, R.; Jablonkai, E.; Keglevich, G. Synthesis of n-butyl ester and n-butylamide of methyl-phenylphosphinic acid: Two case studies. Synth. Commun. 2016, 46, 766-774, DOI: 10.1080/00397911.2016.1171361.

30. Zhang, Q.; Zhang, S.; Deng, Y. Recent advances in ionic liquid catalysis. Green Chem. 2011, 13, 2619-2637, DOI: $10.1039 / \mathrm{c} 1 \mathrm{gc15334j}$.

31. Martínez-Palou, R. Ionic liquid and Microwave-Assisted Organic Synthesis: A "Green" and synergic couple. J. Mex. Chem. Soc. 2007, 51, 252-264, ISSN 1870-249X.

32. Chen, Y.; Zu, Y.; Fu, Y.; Zhang, X.; Yu, P.; Sun, G.; Efferth, T. Efficient Lewis acid ionic liquid-catalyzed synthesis of the key intermediate of coenzyme $Q(10)$ under microwave irradiation. Molecules 2010, 15, 9486-9495, DOI: 10.3390/molecules15129486.

33. Kiss, N.Z.; Keglevich, G. Microwave-assisted direct esterification of cyclic phosphinic acids in the presence of ionic liquids. Tetrahedron Lett. 2016, 57, 971-974, DOI: 10.1016/j.tetlet.2016.01.044.

34. Kiss, N.Z.; Rádai, Z.; Tihanyi, I.; Szabó, T.; Keglevich, G. (under publication).

35. Kiss, N.Z.; Mucsi, Z.; Böttger, É.; Drahos, L.; Keglevich, G. A three-step conversion of phenyl-1H-phosphinic acid to dialkyl phenylphosphonates including two microwave-assisted direct esterification steps. Curr. Org. Synth. 2014, 11, 767-772, DOI: 10.2174/1570179410666131212231130.

36. Mucsi, Z.; Kiss, N.Z.; Keglevich, G. A quantum chemical study on the mechanism and energetics of the direct esterification, thioesterification and amidation of 1-hydroxy-3-methyl-3-phospholene 1-oxide. RSC Adv. 2014, 4, 11948-11954, DOI: 10.1039/C3RA47456A.

37. Keglevich, G.; Kiss, N.Z.; Drahos L.; Körtvélyesi T. Direct esterification of phosphinic acids under microwave conditions: extension to the synthesis of thiophosphinates and new mechanistic insights. Tetrahedron Lett. 2013, 54, 466-469, DOI: 10.1016/j.tetlet.2012.11.054.

38. Kiss, N.Z.; Rádai, Z.; Mucsi, Z.; Keglevich, G. Synthesis of bis(phosphinoyl)amines and phosphinoyl-phosphorylamines by the $N$-phosphinoylation and $N$-phosphorylation of 1-alkylamino-2,5-dihydro-1H-phosphole 1-oxides. Heteroatom Chem. 2015, 26, 134-141, DOI: 10.1002/hc.21229.

39. Keglevich, G.; Mucsi, Z. Interpretation of the rate enhancing effect of microwaves. In Microwave Chemistry; Cravotto, G.; Carnaroglio, D., Eds.; De Gruyter: Berlin, 2017; Ch. 4, in press.

40. Keglevich, G.; Greiner, I.; Mucsi, Z. An interpretation of the rate enhancing effect of microwaves Modelling the distribution and effect of local overheating - A case study. current organic chemistry Curr. Org. Chem. 2015, 19, 1436-1440, DOI: 10.2174/1385272819666150528004505.

41. Keglevich, G.; Bálint, E.; Tajti, Á.; Mátravölgyi, B.; Balogh, G. T.; Bálint, M.; Ilia, G. Microwave-assisted alcoholysis of dialkyl phosphites by ethylene glycol and ethanolamine. Pure Appl. Chem. 2014, 86, 1723-1728, DOI: 10.1515/pac-2014-0601.

42. Keglevich, G.; Kiss, N.Z.; Mucsi, Z. A comparative study on the thermal and microwave-assisted direct esterification of phenyl- $H$-phosphinic acid - modeling the rate enhancing effect of MWs. Curr. Phys. Chem. 2016, 6, 307-311, DOI: 10.2174/1877946806666161103142955.

(C) 2017 by the authors. Submitted for possible open access publication under the terms and conditions of the Creative Commons Attribution (CC BY) license (http://creativecommons.org/licenses/by/4.0/). 